\title{
A study on self esteem and adjustment in children with learning disability
}

\author{
Alisha Parshurami ${ }^{1}$ \\ ${ }^{1}$ Post Graduate student, Department of Psychology, Maniben Nanavati Women's College, Mumbai \\ E-mail - alishaparshurami22@gmail.com
}

\section{ABSTRACT}

Learning Disabilities is a general term that refers to a heterogeneous group of disorders manifested by significant difficulties in the acquisition and use of listening, speaking, reading, writing, reasoning, or mathematical skills. Studies have shown that children suffering from Learning Disorder have low self-esteem and have various adjustment problems. The study was carried out in 110 children with aims to explore the self-esteem and adjustment in girls and boys with Learning Disability. The scales used were Adjustment Inventory for School Students \& Rosenberg's Self-esteem Scale. It was observed that self esteem was low in children with $L D$ compared to those not having $L D$. On the other hand, it was found that boys with Learning Disability had higher self-esteem as compared to boys without Learning Disability. Girls, however, had lower self-esteem as compared to girls without Learning Disability.

Keywords: Self-esteem, adjustment, learning disability.

\section{INTRODUCTION}

Learning Disabilities is a general term that refers to a heterogeneous group of disorders manifested by significant difficulties in the acquisition and use of listening, speaking, reading, writing, reasoning, or mathematical skills. These disorders are intrinsic to the individual, presumed to be due to central nervous system dysfunction and occur across the life-span. Problems in self-regulatory behaviors, social perception, and social interaction may exist with learning disabilities but do not, by themselves, constitute a learning disability [1].

The core self-evaluations approach includes self-esteem as one of four dimensions that comprise one's fundamental appraisal of oneself, along with locus of control, neuroticism, and self-efficacy. The concept of core self-evaluations has proven to have the ability to predict several work outcomes, specifically, job satisfaction and job performance. Self-esteem may, in fact, be one of the most essential core self-evaluation dimensions because it is the overall value one feels about oneself as a person [2].

A recent study has shown that emotional and behavioral adjustment profile varies among children with different types of LD: namely, single and multiple LD. Those having 
multiple reading and math disabilities and math disability only category showed significantly more impairment on depression and immature behavior measures than adolescents with reading disability only or adolescents with typical achievement [3]. Another study has provided evidence for higher levels of emotional problems as well as behavioral difficulties and attention problems, among children with dyslexia cases [4]. Deficits in social skills have also been found to exist at significantly high rates among children with learning disabilities [5]. There are certain common characteristics amongst those who exhibit deficits in social skills do like according to Bruck, children with more severe manifestations of LD are likely to manifest both an increased number of and increased severity of social skills deficits. Also the gender of the child appears to be a factor, with evidence suggesting that girls with LD are more likely to have social adjustment problems [6].

Many studies have examined the association between attachment style and socioemotional adjustment. Studies have indicated that securely attached individuals clearly exhibit better mental health, higher levels of psychological well-being, and more signs of social and emotional adjustment than do individuals with an avoidant or anxious attachment style $[7,8]$. Studies among high-risk children have highlighted the role of insecure attachment styles as a vulnerability factor in increasing maladjustment in the social, emotional, and cognitive domains $[9,10]$.

Thus we carried out our study with following aims and objectives:

- To study self esteem and adjustment problems amongst children having Learning Disability.

- To study whether gender has relationship with self esteem and adjustment problems in them.

\section{METHODOLOGY}

The study was conducted at various Learning Disability Clinics and/or Government Hospitals in Mumbai. After taking informed consent from the parents total 110 children were studied. The study had 2(gender) X 2(learning disability) multivariate factorial design. Gender had 2 levels; girls and boys and learning disability had 2 levels; present and absent. The dependent variables were self-esteem and adjustment.

\section{Scales used were:}

Rosenberg's Self-esteem Scale: The Rosenberg Self-esteem scale is a widely used self-report instrument for evaluating individual's self-esteem, developed by Rosenberg in the year 1965. It is a measure of global self-esteem. It consists of 10 statements related to overall feelings of self-worth or self-acceptance. The scale has 0.82 to 0.88 test-retest reliability. The internal consistency range is from 0.77 to 0.88 . The criterion validity is 0.55 . It is correlated with anxiety (0.64) and depression (0.54) [11].

Adjustment Inventory for School Students (AISS): The inventory seeks to segregate well-adjusted secondary school students (age group 14 to 18 years) from poorly adjusted students in the 3 areas of adjustment: Emotional, Social and Educational. It consists of 60 items, 20 items in each area of adjustment. The inventory has 0.95 split -half reliability. The product moment coefficient of correlation was obtained to be 0.51 . The inventory was developed by Sinha \& Singh (2005). For each response indicative of adjustment ' 0 ' is given otherwise ' 1 ' is given. While high scores on 
AISS indicate poor levels of adjustment, low scores indicate good adjustment. The minimum score on the AISS is 0 while the maximum score is 60 [12].

\section{Analysis of Data}

MANOVA was used to test the relationship because there were several variables.

\section{RESULTS}

In this group of 110 students, the mean score for adjustment was $18.70(\mathrm{SD}=7.184)$. The maximum score on adjustment was 37 and the minimum score was 6 . The mean score for self-esteem was $18.35(S D=4.163)$. The maximum score on self-esteem was 29 and the minimum score was 8 [Table 1].

MANOVA revealed a significant effect between LD code (i.e. children with learning disability and children without learning disability) and Adjustment $[F(1$, $106)=20.034, p<0.0001]$. There was no significant effect between LD code (i.e. children with learning disability and children without learning disability) and Self-Esteem $[F(1,106)=2.658, p=0.106]$. There was no significant effect between Gender and adjustment $[F(1,106)=2.415, p=0.123]$. There was no significant effect between Gender and Self-Esteem $[F(1,106)=0.014,0.905]$. There was no significant effect between the interactions of LD code (i.e. children with learning disability and children without learning disability) and Gender on Adjustment $[F(1,106)=0.008, p=0.928]$. But there was significant effect between the interactions of LD code (i.e. children with learning disability and children without learning disability) and Gender on Self-Esteem [F $(1,106)=5.211,0.024]$.

Table 1: Means and Standard Deviation of various parameters

\begin{tabular}{|lllll|}
\hline N=110 & Mean & Standard Deviation & Minimum & Maximum \\
\hline Age & 15.13 & 0.718 & 14 & 16 \\
\hline AISS Score & 18.70 & 7.184 & 6 & 37 \\
\hline Self Esteem Score & 18.35 & 4.163 & 8 & 29 \\
\hline
\end{tabular}

Table 2: Correlation between adjustment and self-esteem

\begin{tabular}{|ll|}
\hline $\mathbf{N}=110$ & Self- Esteem \\
\hline AISS & $r=-0.321^{* *}$ \\
& $p=0.001$ \\
& \\
\hline
\end{tabular}

\section{DISCUSSION}

The study aimed to explore the self-esteem and adjustment of boys and girls with Learning Disability, compared to children of either gender without Learning Disability. The statistics used to analyze the obtained data was MANOVA. Our study showed that children with Learning Disability will have low adjustment as compared to those without Learning Disability. A study by Sauver et. al. found that boys and girls appear to be differentially susceptible to Reading Disability risk factors, suggesting that the biologic processes leading to Reading Disability may differ between boys and girls [13]. Research has indicated boys were at least two times more likely to have Reading 
Disability compared with girls [14]. Others have demonstrated that men and women differ in the areas of the brain that are activated during phonologic processing; men tend to activate the left inferior frontal gyrus of the brain, while women activate both the left and the right inferior frontal gyrus. Therefore, girls may be better able to compensate for a deficit in reading compared with boys [15].

Adjustment among people with learning disability was examined in a study and it was found that adolescents with multiple learning disabilities reported poorer functioning on school maladjustment, emotional symptoms index, and attitude to school, a typicality and depression when compared to peers with a single learning disability [16]. Our study showed that self esteem was low in children with LD compared to those not having LD. On the other hand, it was found that boys with Learning Disability had higher self-esteem as compared to boys without Learning Disability. Girls, however, had lower self-esteem as compared to girls without Learning Disability. But this was not statistically significant. In a study by Harald Valas, it was seen that students with learning disabilities and low achieving students, as compared to students with no learning disabilities and the non-low achieving students were less accepted by their peers and also had lower self-esteem and they felt lonelier [17]. A number of studies have, in fact, found lower self-esteem in subjects with LD compared with non-LD samples, using a variety of scales [18].

The main limitation of the study was that the scales used were self-report type. The children had to fill in the scales on their own. Some children may not have asked if they had some doubts during the filling up of the scales. The second limitation of the study was that all the data was not obtained from one institution but various institutions were visited across Mumbai.

The trends which were found suggest that boys with Learning Disability had low adjustment as compared to boys without Learning Disability; however, boys with Learning Disability had higher self-esteem as compared to boys without Learning Disability. Girls with Learning Disability had low adjustment as compared to girls without Learning Disability; also girls with Learning Disability had low self-esteem as compared to girls without Learning Disability. It was also seen that Learning Disability and Gender did not have statistically significant effect on the self-esteem. But there was a significant effect of interactions of Learning Disability and Gender on adjustment.

\section{REFERENCES}

1. John A, Sadasivan A, Sukumaran B, Bhola P, David NJ, Manickam LSS. Practice Guidelines: Learning Disability. Indian Journal of Clinical Psychology 2013;40(1):65-88.

2. Judge TA, Locke EA, Durham CC. The dispositional causes of job satisfaction: A core evaluations approach. Res Organiz Behav 1997;19:151-88.

3. Martínez RS, Semrud-Clikeman M. Emotional adjustment and school functioning of young adolescents with multiple versus single learning disabilities. J Learn Disabil. 2004; 37(5):411-20.

4. Heiervang E, Stevenson J, Lund A, Hugdahl K. Behaviour problems in children with dyslexia. Nord J Psychiatry 2001;55(4):251-6.

5. Gresham, F.M. Conceptual issues in the assessment of social competence in children. In Children's social behavior: Development, assessment, and modification. P. Strain, M. Guralink, and H. Walker, eds. New York: Academic Press, 1986, pp. 143-86.

6. Bruck, M. Social and emotional adjustments of learning disabled children: A review of the issues. In Handbook of cognitive, social, and neuropsychological aspects of learning disabilities. S.J. Ceci, ed., Hillsdale, NJ: Erlbaum, 1986, pp. 230-50. 
7. Erickson, MF, Sroufe LA, Egeland B. The relationship between quality of attachment and behavior problems in preschool in a high-risk sample. Monogr Soc Res Child Dev 1985;9:147-66.

8. Mikulincer M, Florian V. Attachment style and affect regulation: Implications for coping with stress and mental health. Blackwell handbook of social psychology: Interpersonal processes, 2001, 535-557.

9. Lyons-Ruth K, Alpern L, Repacholi B. Disorganized infant attachment classification and maternal psychosocial problems as predictors of hostile-aggressive behavior in the preschool classroom. Child Dev 1993;64(2):572-85.

10. Moss E, Parent S, Gosselin C, Rousseau D, St-Laurent D. Attachment and teacher-reported behavior problems during the preschool and early school-age period. Dev Psychopath $1996 ; 8(3): 511-25$.

11. Rosenberg M. Society and the adolescent self-image. Princeton, NJ: Princeton University Press ; 1965.

12. Sinha AKP, Singh RP. Manual for Adjustment Inventory for School Students. Agra: National Psychological Corporation ; 2005.

13. St Sauver JL, Katusic SK, Barbaresi WJ, Colligan RC, Jacobsen SJ. Boy/girl differences in risk for reading disability: potential clues? Am J Epidemiol 2001;154(9):787-94.

14. Flannery KA, Liederman J, Daly $L$, et al. Male prevalence for reading disability is found in a large sample of black and white children free from ascertainment bias. J Int Neuropsychol Soc 2000;6:433-42.

15. Shaywitz SE, Shaywitz BA, Fletcher JM, et al. Prevalence of reading disability in boys and girls. Results of the Connecticut Longitudinal Study. JAMA 1990;264:998-1002.

16. Martínez RS, Semrud-Clikeman M. Emotional adjustment and school functioning of young adolescents with multiple versus single learning disabilities. J Learn Disabil 2004; $37(5): 411-20$.

17. Valas H. Students with learning disabilities and low achieving students; peer acceptance, loneliness, self-esteem and depression. J Soc Psychol Educn 1999;3:173-92.

18. Grolnick WS, Ryan RM. Self-perceptions, motivation, and adjustment in children with learning disabilities: a multiple group comparison study. J Learn Disabil 1990;23(3):17784.

Acknowledgements - Nil

Conflict of Interest - Nil

Funding - Nil. 